\title{
What Do City Planners Need to Know? When Do They Need to Know It?
}

\author{
Chade Saghir ${ }^{1,2}$ \& Gary Sands ${ }^{2}$ \\ ${ }^{1}$ College of Education, Instructional Technology, Wayne State University, Detroit, MI, United States \\ ${ }^{2}$ Department of Urban Studies and Planning, Wayne State University, Detroit, MI, United States \\ Correspondence: Chade Saghir, Department of Urban Studies and Planning, Wayne State University, Detroit, MI, \\ United States
}

Received: December 10, 2014

Accepted: January 4, $2015 \quad$ Available online: January 27, 2015

doi:10.11114/ijsss.v3i2.652

URL: http://dx.doi.org/10.11114/ijsss.v3i2.652

\begin{abstract}
Do university planning programs provide their graduates with the knowledge, skills and values they will require in their professional careers? A national on-line survey of planning practitioners finds that there is a close correspondence between what planners consider to be important and the curriculum standards and criteria of the Planning Accreditation Board, which are the model for the curricula of accredited Planning degrees. Individual elements are ranked high in importance, regardless of respondents' educational and occupational characteristics. Both Globalization and Sustainability/Environmental Quality received relatively low importance rankings from respondents; this suggests areas for increased attention by universities and continuing education.
\end{abstract}

Keywords: urban planning education, urban planning curriculum, professional planning competencies, planning Accreditation Board

\section{Introduction}

The professional practice of city planning is concerned with the management of change in an urban setting to enable a community to reach, or at least move closer to, its goals. Planning explicitly recognizes the limitations of the private market as a means of realizing a community's vision and the necessity for public interventions in the market. Such interventions take a variety of forms, including creation of institutional structures (zoning and development regulations), public investments and incentives to encourage desired private investments. Community master plans articulate the community vision.

City planning has traditionally focused on dealing with positive changes - growth and new development. The profession has also become more involved with mitigating decline and encouraging revitalization. Economic development - to attract jobs and investments and to promote neighborhood and community revitalization where markets have failed has become an important sub-field of planning.

This conceptualization of professional planning practice poses challenges for planning educators. Planning education must provide graduates with the knowledge, skills and values necessary to achieve a future that is not currently known or even readily anticipated. It is challenging to provide planning students with the range of competencies needed to address current planning problems; anticipating the knowledge, skill and values needed to address unknown future circumstances is clearly even more difficult. Designing a curriculum that meets these requirements is not a simple or easy task. But this is precisely what university planning programs must do to prepare students for planning careers, not just for their first job.

This task is complicated by the wide range of topics that fall within the purview of planning professional. APA has identified 23 functional areas of practice including: community development, comprehensive or long range planning, development regulation or administration, economic development and revitalization, land use, policy planning, social and health services, transportation, and urban design (American Planning Association, 2011). APA has also identified 13 spatial areas of practice, from national level to small towns and neighborhoods (American Planning Association, 2011). Clearly, no single planning curriculum can address all of the possible combinations. 
Glazer (1974) raised the question of a gap between planning education and professional practice. Since the early 1980's, a number of studies have attempted to address this issue (Krueckeberg, 1984; Alonso, 1986; Brooks, 1988; Glasmeier and Kahn, 1989; Baum, 1997; Hall, 1989; Ozawa and Seltzer, 1999; Guzzetta \& Bollens, 2003). Kaufman and Simons (1995) surveyed university planning programs in the US and Canada, as well as American Institute of Certified Planners (AICP) practitioners in nonacademic positions, on the teaching and use of quantitative research methods (QRM) in the field of planning, respectively. A total of 43 of the planning programs as well as 106 planning practitioners participated in the survey (Kaufman \& Simons, 1995). The study found that there was generally not a balance between which quantitative methods were included in academic curriculum and which were used by practicing planners. Ozawa and Seltzer (1999) found that planning employers seeking entry level planners are looking for "planners with technical skills, but skills of synthesis and communication rather than merely analysis and dissemination" (p. 264). This suggests that the job of a planner "is an interactive one" (Ozawa \& Seltzer, 1999, p. 264). Empirical studies assessing the education or training needs of planning professions are not the focus of the published studies.

\subsection{Planning Accreditation Board}

The most important effort to define a comprehensive city planning curriculum is the accreditation standards of the Planning Accreditation Board (PAB). The PAB is a co-operative undertaking sponsored jointly by two organizations: the Association of Collegiate Schools of Planning (ACSP), the American Planning Association (APA) and APA's professional institute, the American Institute of Certified Planners (AICP). PAB (2006) describes ACSP as the national membership organization of universities that award degrees in planning and publishes the Journal of Planning Education and Research (p. 6). ACSP has 134 members, including 20 foreign universities; 76 of these programs are accredited. APA is "the national organization of professional practitioners, educators, students, elected officials, and citizens who share a common concern for APA's primary objective: to advance the art and science of planning for the comprehensive development of communities, regions, states, and the nation" (PAB, 2006, 6). AICP is "the American Planning Association's professional institute, providing recognized leadership nationwide in the certification of professional planners, ethics, professional development, planning education, and the standards of planning practice (PAB, 2006, 5). Thus, the PAB structure reflects the belief that all parties to the planning enterprise - practitioners, educators, students, elected officials, and citizens - have a vital stake in the quality of the nation's programs of planning education (PAB, 2006, 5).

The PAB has established standards for the accreditation of professional bachelor's and master's degrees in planning. In addition to curriculum content, accreditation standards also address administrative organization, faculty and student qualifications and other topics. These standards and guidelines have been developed collaboratively with the constituent organizations and cover student and faculty, resources and administrative policy requirements, as well as curriculum; this paper considers only the curriculum guidelines. PAB does not dictate specifically how to incorporate the competencies in the planning curriculum; however, each planning program must regularly undertake a self study to demonstrate how their curriculum incorporates them.

In 2012, the PAB implemented new accreditation standards. Most of the changes related to items other than the required curriculum content. To be granted accreditation by PAB under the current guidelines, a professional planning curriculum must address the following elements ${ }^{\mathrm{i}}$ :

1. General planning knowledge: the comprehension, representation, and use of ideas and information in the planning field, including appropriate perspectives from history, social science, and the design professions.

2. Planning skills: the use and application of knowledge to perform specific tasks required in the practice of planning.

3. Values and ethics: incorporate issues of diversity and social justice into the curriculum.

The PAB standards constitute competencies, defined as "a set of related knowledge, skills, and attitudes that enable one to effectively perform the activities of a given occupation or job function to the standards expected in employment" (Richey, et al., 2001, 31).

\subsection{Research Questions}

This paper will consider whether the PAB standards are indeed important and relevant to professional planning practice. Relevancy is assessed based on the time spent in the actual use of a particular competency. A competency is judged to be important if planning professional consider that it is necessary for planning practice.

Because the accreditation standards have been developed collaboratively, there is at least a reasonable presumption of their validity. ${ }^{\text {ii }}$ But are these views widely held by practicing planners? Or do they represent abstract ideals that are important to a few but largely irrelevant to the day-to-day work of planners? More specifically: 
- Are the specified planning competencies regularly used by planners in their professional practice? If not, could some be eliminated?

- Are there core competencies that are important to every professional planner? Or are some competencies important primarily to particular subsets of planners, defined by planning specialization, experience, employment, etc.?

Before the summary results of the survey are presented, we will briefly describe our a priori expectations for the three separate PAB categories of Knowledge, Skills and Values. The Knowledge component identifies broad factual categories, four of which are specific to Planning: Purpose of Planning, Planning Theory, Future Methods and Law. ${ }^{\text {iii }}$ The other three have a broader perspective: Human Settlements, the Future, and Globalization.

These latter, more general, competencies do not typically represent day-to-day tasks for planners; rather, they provide the intellectual context for the specific actions and activities that make up daily work activities of most planners. For example, understanding the impacts of globalization on cities is an important consideration in framing planners' outlook. That does not, however, mean this knowledge is consciously applied in every site plan review or zoning request. We expect that most planners would report that little of their time was spent using these knowledge competencies but they may be considered important.

The PAB Skills elements include a similar division between planning focused (Plan Creation/Implementation, Planning Process Methods) and more generic (Research, Communication, Analytic Methods, and Leadership) competencies. These Skills are expected to be what planners do on a daily basis. Planning specialists may use one or two particular Skills that they consider to be important, while skills used less frequently would be assigned a lower ranking.

The Values elements (Professional Ethics and Responsibility, Governance/Participation, Sustainability/Environmental Quality, Growth/Development, and Social Justice) are foundational; that is, they should frame the decisions and recommendations that planners make, but do not necessarily translate into specific tasks. Because shared values are essential to the definition of a profession, we would expect each of these values to be assigned high rankings for importance even though little time is spent on them. The expectations for each category are summarized in Table 1.

Table 1. Anticipated Survey Results for PAB Knowledge, Skills and Values

\begin{tabular}{lll}
\hline Element & Importance & Time Spent \\
\hline Knowledge & Higher for Planning specific; Lower for others & Most Low; Law higher for some \\
Skills & Variable, depending on respondent responsibilities & Variable, depending on respondent responsibilities \\
Values & High & Low \\
\hline
\end{tabular}

\section{Methodology}

The survey tested these expected results by asking respondents to assess both the relative importance of each competency and the frequency with which they used each one. For each competency, survey respondents were asked to rank "time spent" on a six point Likert-type scale ranging from never used (1) to frequently used (6). A similar scale was used to measure the respondents' assessment of the importance of each competency. The mean and median were calculated for each of the competencies.

The research focused on planning practitioners in the United States, using a web based survey (via Zoomerang). A pilot study was conducted in May 2012 to test the survey instrument and establish content validity. Sixteen experienced planners were asked to evaluate the survey. Panel members were currently employed in planning, with a minimum of ten years of professional planning experience in public, private and nonprofit sectors. Fourteen responded with constructive feedback. The survey was modified to account for changes the experts deemed necessary. The main survey was administered during June and July 2012. This survey methodology is appropriate for the population being surveyed (Guerra-Lopez, 2007). The questionnaire format used in this study was originally developed to identify and prioritize training needs of employees an engineering firm (Allen, 1990).

An e-mail list of professional planners was acquired from Email Marketing List, an online company that provides email lists by standard industrial classification (SIC) code. The SIC code acquired was 953204: City Government Urban Planning and Development. The list contained 3,452 valid e-mail addresses of urban planning practitioners across the country in private, public and nonprofit sectors. There were 270 valid responses to the survey, resulting in a $7.8 \%$ response rate and a calculated margin of error is $+/-5.73 \%$ at a $95 \%$ confidence level. ${ }^{\text {iv }}$ 


\section{Results}

The typical respondent to the survey was a male, mid-career, professional planner working for a public agency. The average age (46 years) and years of experience (17 years) suggest that respondents have sufficient experience to provide knowledgeable answers to the survey. Almost two-thirds (65\%) of the respondents were male. There were, however, too few non-white and Hispanic respondents to provide reliable results separately for these groups. The professional status of the respondents is indicated by the proportion of AICP members (53.9\%) among respondents.

Just over one-quarter of the respondents reported that their highest degree was a BA. Almost half had earned a Master's degree in planning; more than 22 percent have a graduate degree in another field. Three out of five respondents indicated that their highest degree was in Planning. About 22 percent held some other graduate degree. Three out of five respondents have planning as the major field for their highest degree; other fields (including public administration, geography, architecture and environmental sciences) represented less than ten percent of respondents.

Table 2. Median and Mean Ranking Scores for Knowledge Competencies

\begin{tabular}{lllll}
\hline & Importance & \multicolumn{2}{c}{ Time Spent } \\
\hline Knowledge Competency & Mean & Median & Mean & Median \\
Planning Law (Law) & 4.87 & 5.00 & 3.78 & 4.00 \\
Purpose and Meaning of Planning (Purpose) & 4.75 & 5.00 & 3.59 & 3.00 \\
Human Settlements & 4.67 & 5.00 & 3.55 & 4.00 \\
The Future (Future Methods) & 4.60 & 5.00 & 3.55 & 4.00 \\
Planning Theory (Theory) & 4.59 & 5.00 & 3.38 & 3.00 \\
The Future & 4.36 & 5.00 & 3.29 & 3.00 \\
Global Dimensions of Planning (Globalization) & 3.18 & 3.00 & 2.33 & 2.00
\end{tabular}

The largest single Planning field reported was Economic Development (39.6\%) planning. Land Use planning accounted for one-fifth of the responses, followed by Transportation (16.7\%), Community (13.0\%) and Environmental (9.6\%) planning. Seven out of ten respondents work for a public sector employer, with an additional 17 percent in the private sector.

\subsection{Rankings of Competencies}

\subsubsection{Knowledge Elements}

The Knowledge competency that ranked highest in both importance and time spent was knowledge of planning Law. The lowest scores were given to knowledge of Globalization, which had the lowest importance ranking of any competency. It was the only one of the 18 competencies that had mean and median rankings less than 3.0 for time spent.

\subsubsection{Skills Elements}

All six Skills received relatively high scores for importance and lower ranking for time spent. Communication skills had the highest rating for both importance and time spent. Its average rank (5.24) was the highest among all 18 PAB competencies; it is the only one with a median rank of 6 . The skills competency that scored the lowest with respect to both importance and time spent was Research skills.

Table 3. Median and Mean Scores for Skills Competencies

\begin{tabular}{lllll}
\hline \multirow{2}{*}{ Skills Competency } & \multicolumn{3}{c}{ Importance } & \multicolumn{2}{c}{ Time Spent } \\
& Mean & Median & Mean & Median \\
\hline Written, Oral and Graphic Communication (Communication) & 5.24 & 6.00 & 4.31 & 4.00 \\
Planning Process Methods (Process Methods) & 4.91 & 5.00 & 3.91 & 4.00 \\
Quantitative and Qualitative Methods (Analytical Methods) & 4.74 & 5.00 & 3.76 & 4.00 \\
Plan Creation and Implementation & 4.57 & 5.00 & 3.65 & 4.00 \\
Leadership & 4.49 & 5.00 & 3.51 & 3.00 \\
Research & 4.09 & 4.00 & 3.30 & 3.00 \\
\hline
\end{tabular}




\subsubsection{Values}

For Values competencies, the rank orders for importance and time spent are not the same. The value competency that scored the highest with respect to importance was Growth/ development, closely followed by Ethics. These two competencies, along with Social justice, scored considerably higher on the importance scale than on the time spent. For Governance/participation and Sustainability/environmental quality, the scores are reversed: the importance rating is substantially lower than the time spent score. Sustainability/environmental quality had a median time spent rank of 5 but was the only competency with a median importance score of 3.

Table 4. Median and Mean Scores for Values Competencies

\begin{tabular}{lllll} 
& & & & \multicolumn{2}{l}{ Time Spent } \\
Value Competency & Mean & Median & Mean & Median \\
\hline Growth and Development & 4.56 & 5.00 & 3.52 & 3.00 \\
Professional Ethics and Responsibility (Ethics) & 4.54 & 5.00 & 3.38 & 3.00 \\
Social Justice & 4.21 & 4.00 & 3.22 & 3.00 \\
Governance and Participation & 4.02 & 4.00 & 4.89 & 5.00 \\
Sustainability and Environmental Quality & 3.32 & 3.00 & 4.46 & 5.00 \\
\hline
\end{tabular}

\subsection{Differences by Subgroup}

The aggregate results present a fairly clear picture of the competencies that are important and relevant to planners: Planning Law, Communication and Growth/Development received the highest rankings; Globalization and Sustainability/Environmental Quality the lowest. There are, however, important differences among sub-groups of planners that are identified below.

\subsection{Experience}

Planners with less than five years of experience ranked Human settlements, Analytical methods and Growth/development highest. More experienced planners consistently assigned the highest importance to Planning law, Communication and Ethics. While it might be expected that beginning planners have a different perspective on what is important, it is somewhat surprising that there is virtually no change once they have passed the five year mark.

\subsection{Education Level}

Planners with a masters' degree in planning differed from non-MUP planners by assigning the highest importance rankings to Purpose of planning and Research competencies. Respondents without an MUP, Planning law and Communication were accorded the highest rankings. Planners with their highest degree in planning ranked Growth/ development highest; those with a different terminal degree rated Ethics highest.

\section{Professional Status}

Planners with AICP membership differed from other respondents on which were the most important competencies. AICP ranked Law highest and planners without AICP ranked Human settlements highest for both amount of time spent and importance. Planners with AICP credentials ranked Process methods as the most important skill competency. AICP members ranked Ethics highest while non-AICP respondents ranked Growth/development highest in importance. Planners with AICP ranked social justice lowest and those without AICP ranked Ethics lowest with respect to time spent on value competences.

\subsection{Planning Field}

Survey respondents were asked to identify their primary planning field, including economic development, environmental, transportation, community, and land use planners. In terms of importance, Economic Development and Land Use planners put Law at the top of their lists. Transportation planners continue to rate knowledge of Future methods highly, but environmental planners ranked Theory as most important. Community planners were diverse in how they spent their time, giving equal ranks to three different competencies: Law, Human Settlements and Future Methods. Economic Development and Land Use planners ranked Law highest. Transportation planners assigned the highest rankings to knowledge of Future Methods.

With respect to specific skills, there is considerably more agreement. Communication skills are what most planners spend their time on; only transportation planners reported that most of their time was spent using a different skill, Analytical methods. All planners, except for environmental planners, ranked Governance/participation most important value for time spent. Environmental planners, not surprisingly, spend the most time on Sustainability/environmental quality. Growth/development topped the importance list for all planners, except for land use planners who stated that Ethics was most important to them. Ethics was also high on the list for environmental planners. 


\subsection{Planning Functions}

These broad Planning fields do not necessarily provide a clear understanding of what planners actually do on their jobs. To gain more insight into differences based on job functions, a factor analysis was performed on the respondents' self-evaluation of their mastery of specific skills. The list of 26 skills was derived from a review of several articles that described specific skills that planners should know (Glasmeier and Kahn 1989; Kaufman and Simons 1995; Ozawa and Seltzer 1999; and Guzzetta and Bollens 2003). As noted previously, we expect that the survey responses would vary, at least to some degree, based on the characteristics of the respondents.

To better define planning specialization, a factor analysis was performed on the respondents' self-reported abilities in 26 functional areas. The results of the factor analysis ${ }^{\mathrm{v}}$ identified five functional categories: Analysis, Management, Communication, Technical, and Generalist. The specific skills and their factor loadings are provided in Appendix A.

Regardless of the respondent's primary planning field, respondents were consistent in identifying items that they considered to be unimportant and that occupied little of their time. Among the knowledge elements, Globalization ranked last (typically by a substantial margin) on both measures. Technical planners ranked Research at the bottom in terms of importance but Leadership skills received the lowest average score for time spent.

\subsection{Employer}

Planners employed by non-profit organizations ranked Future methods highest for importance. While planners in public and private setting ranked research lowest for both amount of time spent and importance, planners in nonprofit setting ranked Plan creation/ implementation lowest with respect to time spent and importance. They also ranked Ethics lowest for time spent, while public and private planners ranked Social justice lowest for time spent. Public planners ranked Ethics highest for importance, while private and non-profit ranked Growth/development as most important.

\subsection{Continuing Education}

When asked about their interest in various types of continuing education opportunities, most respondents indicated a desire to improve specific skills. The high level of importance assigned to Communication skills is reinforced by respondents' desire for continuing education opportunities in this field. One-quarter of all respondents indicated interest, while one in five has an interest in improving writing skills.

\section{Discussion}

Survey respondents considered almost all of the individual competencies to be at least somewhat important. The only overall average scores of less than 4.0 were for Globalization and Sustainability/environmental quality. While the low rankings for Globalization are perhaps related to the local focus of the work of many practicing lanners or the relatively recent emergence of this area of concern, there appears to be little valid rationale for the perceived lack of importance of Sustainability/environmental quality. There was considerable agreement among the respondents with respect to their choices of the most important Knowledge (Law), Skills (Communication) and Values (Growth/development) competencies. There was a similarly high level of agreement on the least important Knowledge (Globalization), Skills (Research) and Values (Sustainability/environmental quality) competencies.

Results for specific subgroups did vary from the predominant responses:

- $\quad$ Planners with less than five years of experience selected Knowledge Values and Skills that differed from those of more experienced planners, Human Settlements, Analytical methods and Growth/development, respectively.

- $\quad$ Planners working in the public sector were more likely to consider Ethics to be of top importance, while those working for non-profits chose Future Methods.

- $\quad$ Planners classified as Technicians chose Growth/Development as the most important Value.

There was also agreement in terms of the amount of time spent on the different competencies. Globalization was the only competency that had a median ranking of less than 3.0 for time spent. For two values, Governance/participation and Sustainability/environmental quality, average time spent is one full rank above its corresponding importance score.

- Transportation planners spend more time on Analytical methods; community planners on Process methods.

- Planners working for non-profit organizations spent less time on Plan creation/implementation and Ethics than public or private sector planners.

Over the past three decades, planning academics have expressed concern that there is a gap between what planners are taught in their degree programs and what they need to know on the job (Krueckeberg 1984; Alonso 1986; Brooks 1988; Glasmeier and Kahn 1989; Baum 1997; Hall 1989; Ozawa and Seltzer 1999; Guzzetta and Bollens 2003; Teitz 1984)? 
This study found that - regardless of educational background, professional status, years of experience or job function planners rate the individual competencies to be highly important, even those that occupied little of their time. This result can generally be viewed positively by the Planning Accreditation Board and its sponsoring organizations. What the $\mathrm{PAB}$ prescribes as standards for the content of University planning curriculum correspond well to the specific competencies that practicing planners consider important.

\section{Implications}

In addition to being generally supportive of the current curriculum standards of the Planning Accreditation Board, the results of the survey suggest some topics that may warrant further consideration:

Communication is, by a wide margin, the skill competency that received the highest rankings for both time spent. In reviewing their curriculum, planning programs might consider the effectiveness of their instruction on this topic. Additional opportunities to improve communication skills through continuing education might be considered.

At the other extreme, knowledge of Globalization is generally considered the least important and has the least time spent of any of the knowledge competencies. Again, improving planning curricula and continuing education opportunities on this topic seems appropriate. Globalization might be considered an emerging concern among planners. As such, its low importance ranking might result from a lack of exposure to the topic and the limited amount of time spent on global development topics by the majority of planners.

Each of the Value competencies receives a surprisingly low ranking in terms of importance; respondents considered Planning Theory to be more important than any of the Values. Arguably, values such as Professional Ethics and Responsibilities, Social Justice, and Sustainability/environmental quality should be central to planning practice. There is a need to find ways to increase awareness of these Values and to ensure that they will be prominent throughout planners' professional careers.

Of the 18 competencies considered, only two had an average time spent ranking larger than the importance ranking, perhaps suggesting that planners feel they spend a disproportionate amount of time on these competencies. Both are included in the values section: understanding the Governance/participation, including elected officials and the public, and Sustainability/environmental quality. This result may simply be due to one too many public hearings or environmental review; or perhaps simply due to overuse of the word sustainability. While the results suggest that greater emphasis on these topics may be required in planning program curricula to inculcate planners with these Values, they might also be given greater emphasis in continuing education programs.

In general, this research demonstrates that the curriculum elements adopted by the PAB in 2012 meet the basic test of relevance to planning practice. Regardless of field, functional area, years of experience or professional membership, planners agree that the PAB competencies are indeed the Knowledge, Skills and Values that are important to practitioners. The relatively low levels of importance assigned to some of the core values of professional planning suggest a need to increase awareness of these topics both at universities and through continuing education. Similarly, planners need a better appreciation of the importance of globalization trends to local planning.

To return to the questions raised by this paper's title: What do planners need to know? Planning practitioners agree that the current PAB curriculum guidelines, as well as the prior curriculum guidelines, do indeed provide an outline of what planners need to know. When do they need to know it? Surprisingly, there are few differences between what beginning planners think is important and what planners with 20 or more years of experience consider important. These competencies are required throughout their professional careers.

\section{References}

Allen, E. L., Ed. (1990). ASTD trainer's toolkit: Needs assessment instruments, Alexandria, VA: American Society for Training and Development.

Alonso, W. (1986). The Unplanned Paths of Planning Schools, The Public Interest, 82, 58-71.

Baum, H. (1997). Social Science, Social Work, and Surgery: Teaching What Students Need to Practice Planning, Journal of the American Planning Association, 63,179-188. http://dx.doi.org/10.1080/01944369708975913

American Planning Association (2011). What is planning? http://www.planning.org/aboutplanning/whatisplanning.htm.

Association of Collegiate Schools of Planning (2009). ACSP Homepage. http://www.acsp.org.

Brooks, M. P. (1988). Four Critical Junctures in the History of the Urban Planning Profession: an Exercise in Hindsight. Journal of the American Planning Association, 54(2), 241 -248. http://dx.doi.org/10.1080/01944368808976481

Glasmeier, A., \& Kahn, T. (1989). Planners in the '80s: Who We Are, Where We Work. Journal of Planning Education and Research, 9(1), 5-17. http://dx.doi.org/10.1177/0739456X8900900101 
Guerra-Lopez, I. (2007). Evaluating impact: Evaluation and continual improvement for performance improvement practitioners. Amherst, MA: HRD Press, Inc.

Guzzetta, J. D., \& Bollens, S. A. (2003). Urban Planners' Skills and Competencies: Are We Different From Other Professions? Does Context Matter? Do We Evolve? Journal of Planning Education and Research, 23(1), 96-106. http://dx.doi.org/10.1177/0739456X03255426

Hall, P. (1989). The Turbulent Eighth Decade: Challenges to American City Planning. Journal of American Planning Association, 55(3), 275-282. http://dx.doi.org/10.1080/01944368908975415

Kaufman, S., \& Simons, R. (1995). Quantitative And Research Methods In Planning: Are Schools Teaching What Practitioners Practice? Journal of Planning Education and Research, 15(1), 17-34. http://dx.doi.org/10.1177/0739456X9501500102

Krueckeberg, D. A. (1984). Planning and the New Depression in the Social Sciences, Journal of Planning Education and Research, 3(1), 78-86. http://dx.doi.org/10.1177/0739456X8400300202

Ozawa, C. P., \& Seltzer, E. P. (1999). Taking Our Bearings: Mapping a Relationship Between Planning Practice, Theory, and Education. Journal of Planning Education and Research, 18(3), 257-66. http://dx.doi.org/10.1177/0739456X9901800307

Planning Accreditation Board. (2013). The accreditation document: Standards and procedures of the planning accreditation board. Chicago, IL: Planning Accreditation Board.

Richey, R. C., Fields, D. C., \& Foxon, M. (2001). Instructional design competencies: The standards. Syracuse, NY: ERIC Clearinghouse on Information and Technology in cooperation with the International Board of Standards for Training, Performance, and Instruction (IBSTPI).

Teitz, M. B. (1984). Planning Education and the Planning Profession. Journal of Planning Education and Research, 3(2), 75-77. http://dx.doi.org/10.1177/0739456X8400300201 
Appendix A Factor Loadings for All Components

\begin{tabular}{|c|c|}
\hline & Communalities \\
\hline \multicolumn{2}{|l|}{ Component 1: Analysis } \\
\hline Forecasting modeling skills & 0.861 \\
\hline Competency in linear regression & 0.819 \\
\hline Geographic information system skills mapping & 0.688 \\
\hline Quantitative research skills & 0.686 \\
\hline Qualitative research skills & 0.593 \\
\hline Advanced policy and analysis skills & 0.512 \\
\hline Scenarios development skills & 0.458 \\
\hline \multicolumn{2}{|l|}{ Component 2: Management } \\
\hline Management skills & 0.850 \\
\hline Leadership skills & 0.801 \\
\hline Organizational development skills & 0.739 \\
\hline Negotiation/mediation skills & 0.599 \\
\hline Problem solving skills & 0.489 \\
\hline \multicolumn{2}{|l|}{ Component 3: Communication } \\
\hline Communicating formally with elected officials & 0.793 \\
\hline Communicating formally with the public & 0.768 \\
\hline Familiarity with laws ordinances and policy & 0.686 \\
\hline Writing for the public skills & 0.574 \\
\hline Verbal communication skills & 0.564 \\
\hline Presentation skills & 0.561 \\
\hline \multicolumn{2}{|l|}{ Component 4: Technical } \\
\hline Competency in basic computer programs & 0.710 \\
\hline Report writing skills & 0.681 \\
\hline Ability to complete quality work on time & 0.577 \\
\hline \multicolumn{2}{|l|}{ Component 5: General Planning } \\
\hline Ability to work with diverse communities & 0.727 \\
\hline Understanding public needs & 0.627 \\
\hline Collaborating with peers to produce a plan & 0.599 \\
\hline \multicolumn{2}{|l|}{ Component 6: Other } \\
\hline Communication using social media & 0.628 \\
\hline Ability to communicate graphically & 0.430 \\
\hline
\end{tabular}

\section{(cc) $\mathrm{BY}$}

This work is licensed under a Creative Commons Attribution 3.0 License.

\footnotetext{
${ }^{\mathrm{i}}$ For more detail on these categories, see Planning Accreditation Board, 2012.

ii Accreditation standards, including curriculum, are made available by the PAB for public comment.

iii The PAB Knowledge element The Future was divided into two separate questions: one dealing with knowledge of the past, present and future (The Future) and the other dealing with methods for influencing the future (Future Methods).

iv Factors contributing to the low response rate include the length of the survey, the time frame (Summer) of the survey, respondents not interested or did not have time to participate, and e-mails going directly into a junk e-mail box.

v Principle component analysis with Varimax rotation.
} 